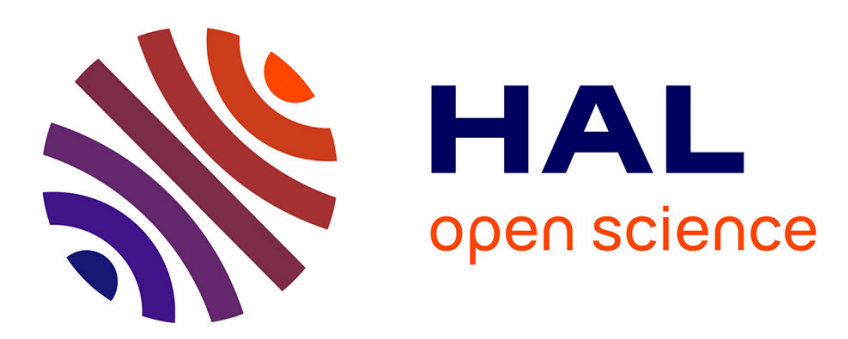

\title{
POINT DEFECT - DISLOCATION INTERACTION IN $\mathrm{MgO}$
}

\author{
M. Gabbay, C. Esnouf, A. Vincent, Gilbert Fantozzi
}

\section{To cite this version:}

M. Gabbay, C. Esnouf, A. Vincent, Gilbert Fantozzi. POINT DEFECT - DISLOCATION INTERACTION IN MgO. Journal de Physique Colloques, 1981, 42 (C5), pp.C5-289-C5-294. 10.1051/jphyscol:1981542 . jpa-00221084

\section{HAL Id: jpa-00221084 https://hal.science/jpa-00221084}

Submitted on 1 Jan 1981

HAL is a multi-disciplinary open access archive for the deposit and dissemination of scientific research documents, whether they are published or not. The documents may come from teaching and research institutions in France or abroad, or from public or private research centers.
L'archive ouverte pluridisciplinaire HAL, est destinée au dépôt et à la diffusion de documents scientifiques de niveau recherche, publiés ou non, émanant des établissements d'enseignement et de recherche français ou étrangers, des laboratoires publics ou privés. 
JOURNAL DE PHYSIQUE

Colloque C5, supplément au n'10, Tome 42, octobre 1981

page $65-289$

POINT DEFECT - DISLOCATION INTERACTION IN MgO

\author{
M. Gabbay, C. Esnouf, A. Vincent and G. Fantozzi \\ Groupe d'Etudes de Métallurgie Physique et Physique des Matériaux, E.R.A. 463 \\ I.N.S.A,, Bât. 502 - 69621 Vizleurbanne Cedex, France
}

\begin{abstract}
Amplitude Dependent Internal Friction has been measured from $77 \mathrm{~K}$ to $593 \mathrm{~K}$ in $\mathrm{Mlg} 0$ single crystals plastically cêormed at room temperature. Experimental resulis have been tested with several tineoretical hodels of dislocation breakaway. A reliable value of interaction energy $(0.5 \mathrm{eV})$ is deduced from the model of Teutonico, Granato and Lücke, but only a partial agreement between experimental results and the model is obtained. For that reason, a numerical analys is of thermonechanical breakaway has been undertaken.
\end{abstract}

1. Introduction.- Different behaviours of mobile dislocations in Mgo single crystals plastically deformed at Room Temperature (R.T.) have been presented in previous papers [1], [2]. Among these aspects, one of the most important is the high sensivity of Internal Friction (IF.) to annealing; for treatments above RT., the level of the IF. spectrum decreases very quickly as annealing temperature increases. Such a reduction of IF. has been already explained by pinning of dislocations with migrating point defects. In our last paper [3], we tried to apply - in order to determine binding energy between pinning point defects and dislocations - the classica) theoretical models (reviewed by Pérez et al. [4]) (such as the models of Granato and Lücke [5], Saul and Bauer [6], Friedel [7]; Teutonico, Granato and Lücke (TGL.) [8]). For the most part, these models did not fit correctly our results along the whole temperature range; besides, the different values of dislocation-point defect interaction energy $U_{0}$, deduced from the few measurements consistent with these models, seemed to be unreliable except for the model of TGL $\left(U_{0}=0.5 \mathrm{eV}\right)$. New experiments have been performed for the present paper and now the theoretical models have been tried on computed local internal friction data. However none of those models fit exactly experimental results. About the TGL model, partial agreement is obtained in the low temperature range. This fact could be due to the thermal breakaway of other species of pinning points activated in the inigher part of temperature range. Moreover these two temperature parts seem to overlap one another making more complex the dissociation of these various processes and their undestanding.

For this reason, numerical analysis of thermomechanical breakaway has been undertaken involving various parameters such as interaction energy $U_{0}$, average loop length, number of pinning points. Ampiitude dependent Internal Friction $\Delta_{H}$ is calculated as a function of stress $\sigma$ for a given temperature. Such a calculation is 
obtained from the statistical depinning and repinning of a dislocation along which several pinning points are non regularly located. Depinning and repinning energies, for each pinning point are determined from the energy diagram considering dislocation-point defect binding energy, tension line and stress work. Then, the results of that numerical analysis are compared to experinental measurements.

2.- Experimental results.- Detailed experimental conditions have been described

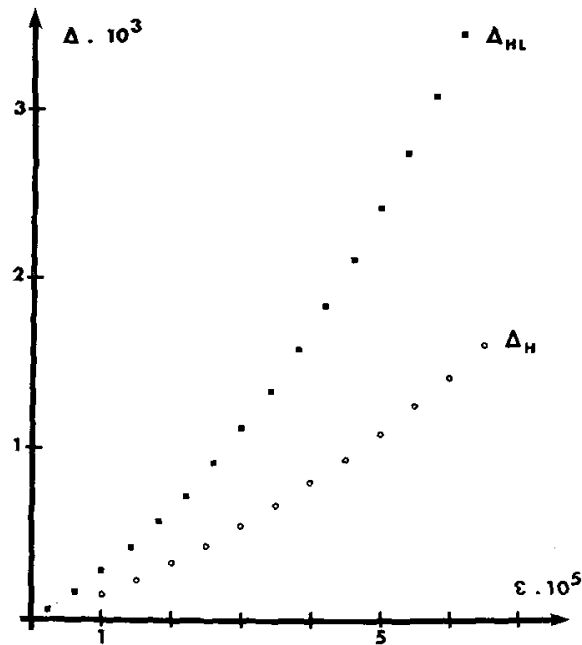

Fig. 1 : Difference between measured $\Delta_{H}$ and computed $\Delta_{\mathrm{HL}}$ by Lazan's method.

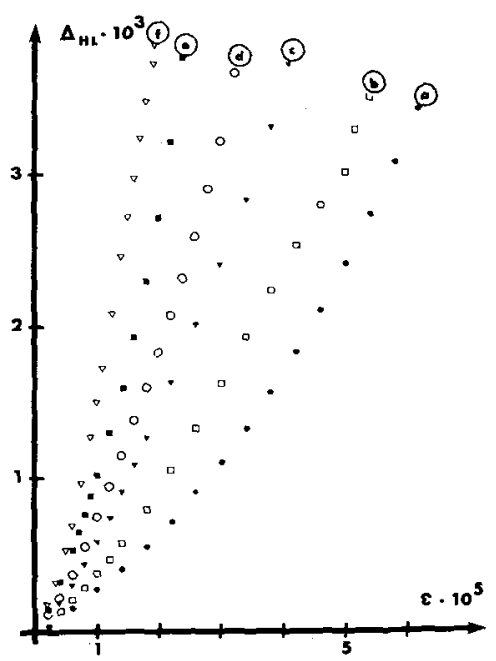

elsewhere 131 . Experimental results are presented using the reat Local Amplitude Dependent Internai Friction $\Delta_{H L}$ corresponding to the strain amplitude $\varepsilon . \Delta_{H L}$ is deduced from amplitude dependent Internal Friction $\Delta_{H}$ (experimentaliy measured) by the Lazan's method $|S|$ leading to the following relation : $\Delta_{H L}=\Delta_{H}+0,77 \Delta_{H} \frac{\partial \Delta_{H}}{\partial \varepsilon}+0,11 \Delta_{H}^{2} \frac{\partial^{2} \Delta_{H}}{\partial \varepsilon^{2}}$

For example, Figure 1 shows the large difference between $\Delta_{H}$ and $\Delta_{H I L}$ plotted versus $\varepsilon$. For each annealing temperature $(293 \mathrm{~K}, 366 \mathrm{~K}$, $429 \mathrm{~K}, 521 \mathrm{~K}, 593 \mathrm{~K})$, a set of $\Delta_{\mathrm{HL}}$ $(\varepsilon)$ curves are plotted for measurements performed between $77 \mathrm{~K}$ and the annealing temperature. Two of these sets of curves are presented in Figures 2 and 3 respectively for the annealing temperatures $293 \mathrm{~K}$ and $593 \mathrm{~K}$. Therma 7 activation of depinning, already observabie on Figures 2 and 3 , is particularly pointed out by the plot of $\Delta_{\mathrm{HL}}$ versus temperature at constant strain amplitude $\varepsilon$ presented on Figure 4. Such $\Delta_{H L}$ (T) curves are obtained from data of Figure 2.

Fig. 2 : After plastic deformation at 293K, variations of $\Delta_{\text {Hil }}$ versus $\varepsilon$ at various temperatures $a: 77 K, b: 102 K$, $c: 151 \mathrm{~K}, \mathrm{~d}: 183 \mathrm{~K}$, e : 240 K, f : 293K. 


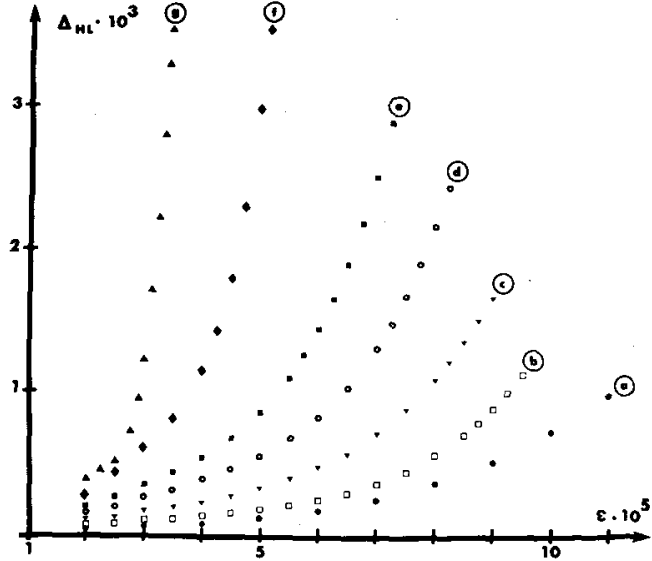

Fig. 3 : After annealing at $593 \mathrm{~K}$, variations of $\Delta_{\text {HL }}$ versus $\varepsilon$ at various temperatures. a : $77 \mathrm{~K}, \mathrm{~b}: 105 \mathrm{~K}, \mathrm{c}: 133 \mathrm{~K}, \mathrm{~d}$ : $193 \mathrm{~K}, \mathrm{e}: 246 \mathrm{~K}, \mathrm{f}: 425 \mathrm{~K}, \mathrm{~g}: 523 \mathrm{~K}$.

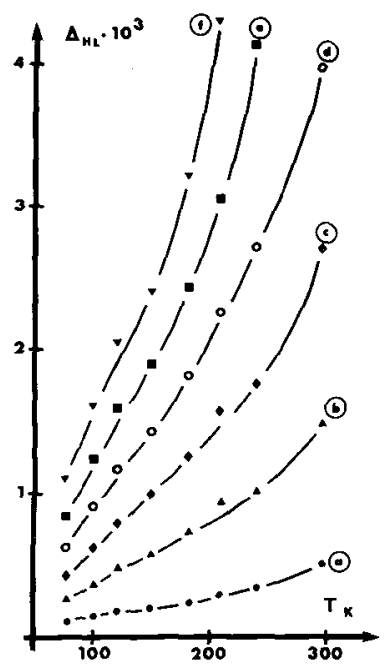

Fig. 4 : After plastic deformation, variations of $\Delta_{H L}$ versus $T$ at various strain amplitudes. a : $5.10^{-6}, b: 10^{-5}$, $c: 1.5 .10^{-5}$, d : $2.10^{-5}$, e : $2.5 .10^{-5}$, $f: 3.10^{-5}$.

Discussion : All the experimental results show obviously that thermal activation is already operative at $77 \mathrm{~K}$. So, only thermally activated models have been tested. For instance the model developped by Saul and Bauer leads to the following expression for $\Delta_{H L}$ :

$$
\Delta_{H L}=\Delta_{0}(1+\sigma v / k T) \exp \left(-U_{0} / k T\right)
$$

where $\sigma$ is the resolved shear stress acting on a dislocation

$v$ is the activation volume

$\Delta_{0}$ is the relaxation strength factor.

This relation is available for early states of depinning. i.e. for the case where the fraction of unpinned 10ops. $f(t)$ is very small $(f(t) \ll 1)$ and for high temperature $(\sigma \mathrm{V} \ll k T)$. Then, $\Delta_{H}$ is expected to vary exponentially with $\frac{1}{T}$. Experimental results fit only partially this model; the value of interaction energy $U_{0}$ deduced from this partial agreement is too small $(0.1 \mathrm{eV})$ comparatively to the temperature range along which thermal activation is operative.

In fact the model of TGL is the most important one that we have used. According to this model, a triangle force-distance law gives a rather good approximation for all stress levels and leads to the activation energy for breakaway: 


$$
U=U_{0}\left(1-\sigma / \sigma_{M}\right)^{2}
$$

with $U_{0}$ interaction energy

$\sigma_{M}$ mechanical depinning stress.

Along the temperature range where the TGL model 10 is valid, such a relation allows us to expect a linear variation of strain amplitude $\varepsilon\left(\varepsilon=\frac{\sigma}{E}\right)$ as a function of $\mathrm{T}^{1 / 2}$ for a given level of $\Delta_{H L}$. Besides, a critical temperature $T_{c}$ can be determined by the intercept of this straight variation with temperature axis i.e. for zero stress. The mathematica] development of this mode 1 [9] links such a critical temperature $T_{c}$ to interaction energy $U_{0}$ with the following relation :

$$
U_{0} \simeq 23 k T_{c}
$$

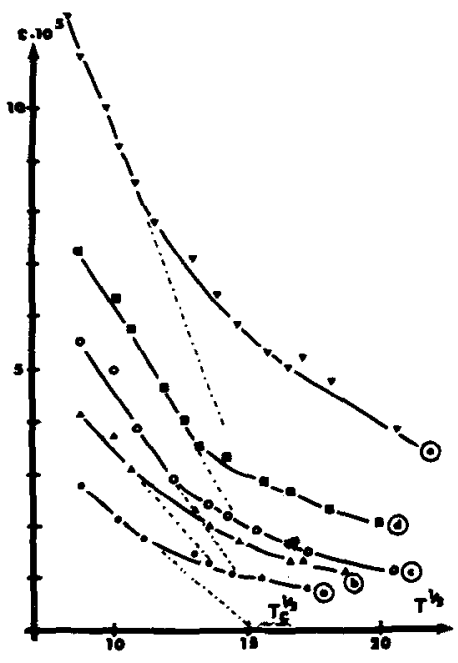

Fig. 5 : Variation of $\varepsilon$ versus $T^{1 / 2}$ for the same level of $\Delta_{\mathrm{HL}}\left(10^{-3}\right)$ and for various annealing states, a : 293K, b : 366K, c : 429k, d: 521K, e: 593K.

In order to get a more extensive analysis of these experimental results, a numerical analysis of internal friction $\Delta_{H}$ due to dislocation breakaway has been undertaken extending a study developed by vincent et al. [11].

Basically, the same triangle force-distance profile (determined in the TGL model) have been applied to interaction between a dislocation and each of its pinning points assumed to be of the same species. The configuration of a pinned dislocation choosen for this calculation is presented on Fig. 6 . The central part is 


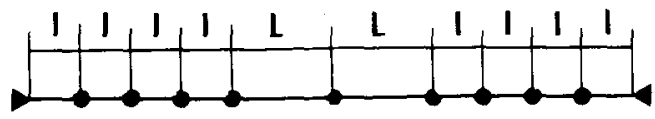

pinned like a symetrical double loop and the other pinning points are regularly spaced.

Fig. 6 : Configuration of a pinned dislocation

A reliable value for interaction energy $U_{0}(0.5 \mathrm{eV})$ is choosen and then, activation energies for depinning $U_{D}$ and repinning $U_{R}$ for each pinning point are computed assuming that the dislocation depinning starts from the largest loop and continues one point at a time. $U_{D}, U_{R}$ are computed by the relations (1), (2):
(1) $U_{D} \propto A U_{0}\left(1-\sigma / \sigma_{D}\right)^{2}$;
(2) $U_{R} \propto B U_{0}\left(\sigma / \sigma_{R}-1\right)^{2}$

where: $A$ and $B$ are coefficients depending upon several parameters which determine the dislocation configuration $\sigma_{D}$ : mechanical stress for depinning

$\sigma_{R}$ : repinning stress.

Both of these stresses depend upon the number of each pinning point. The relations (1) and (2) are valid for $\sigma<\sigma_{D}$ and $\sigma>\sigma_{R}$. The rate theory allows to compute the area swept by dislocations and consequently the strain-stress cycle from which $\Delta_{H}$ is deduced.

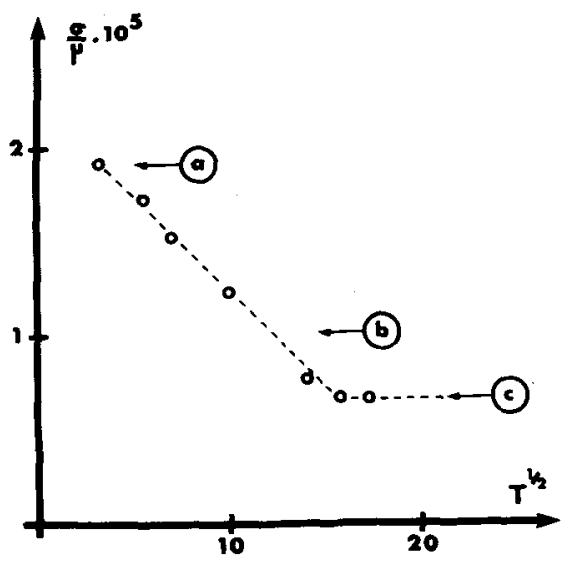

Fig. $7: \sigma / \mu$ versus $T^{1 / 2}$ at constant
Figure 7 shows the first results of this calculation; the applied stress amplitude $\sigma$ is plotted versus $T^{1 / 2}$ at constant level of $\Delta_{\mathrm{H}}$. The main parameters are given hereafter :

- number of pinning points $N=9$

- centrar loop length $L=100 b$ (b: Burger's vector)

- ratio $L / 1=2$.

Along the main part of the temperature range a linear plot is obtained. Such a result is consistent with the reiations (1) and (2). Indeed, for an internal friction level, the depinned fraction (i.e. the depinning probability) is almost constant; thus we have :

$$
\left.U_{D}(\sigma) / T \simeq C \text { constant }\right) \rightarrow \sigma=\sigma_{D}\left(1-C T^{1 / 2}\right)
$$

Unfortunately the critical temperature derived by extrapolation is about $480 \mathrm{~K}$ which leads to about leV for interaction energy; such a value is not consistent with the value choosen for the computation. 


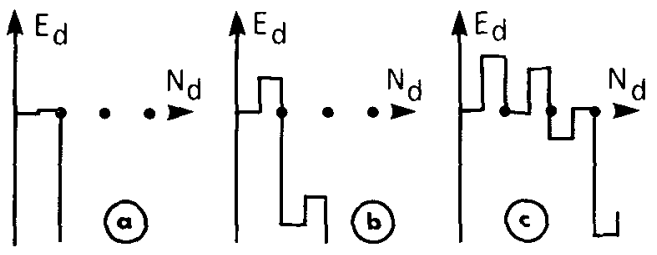

Fig. 3 : Diagrams of energy for various stresses.
Furthermore the diagrams of energy presented on Figure $8 \mathrm{a}, \mathrm{b}$ confirm that in the low temperature range, the thermally activated depinning of the first pinning point is sufficient to initiate the mechanical breakaway of the whole dislocation. Along the high temperature part Figure $8 \mathrm{c}$ shows that successive thermally activated depinnings are

necessary to trigger the whole breakaway. Then, the linearity of the TGL law $\sigma\left(T^{1 / 2}\right)$ is naturally no more expected in these conditions. This result is consistent with the conclusion of Teutonico et a]. [12]. Therefore, this work shows that the analysis of the experimental results according to the TGL model has to be confirmed. In order to fit better the experimental conditions, we must complete our calculation in particular including a distribution of different parameters (10op lengths for example).

\section{References}

(1) GaBbAY, M., ESNOUf, C., FAiNTOZZI, G. J. Phys. Letters, 39, L-271, 1978.

[2] FANTOZZI, G., GABBAY, M., InternaT. Friction and U1trasonic Attenuation in Solids, Editor C.C. Smith, Pergamon Press, Oxford, 1980, p. 395.

(3) GABBAY, M., FANTOZZI, G., $2^{\text {nd }}$ Workshop on "Interaction between Dislocations and Defects in Oxides" St-Didier au Mont d'Or, Sept. 1980, to be published in J. Phys.

[4] Perez, J., PEguin, P., fANTOZZzI, G., GOBII, P.F., Ann. Phys. 5, 303-352, 1970.

[5] GRAiAATO, A.V., LUCKE, K., J. App1. Phys., 27, 583, 1956.

[6] SAUL, R.H., BAUER, C.L., J. App1. Phys., 39, 3, 1469, 1968.

[7] FRIEDEL, J., Conference Teddington, Middlesex, 410, 1963.

[8] TeUtonico, L.J., gRanato, A., LUCKe, K., J. App 1. Phys., 35, 220, 1964.

[9] FANTOZZI, G., Thèse Lyon, 1971.

[10] LUCKE, K., GRANATO, A.V., TEUTONICO, L.J., J. App1. Phys., 11, 5181, 1968.

[11] VinCENT, A., PEREZ, J., Phi1. Mlag. A, 40, 3, 377-397.

[12] TEUTOHICO, L.J., LUCKE, K., HEUSER, F.W., GRANATO, A.V., J. ACOUST. SOC. Am. $45,6,1402-1416,1969$. 